\title{
Performance of The Dispin Models with Automatic Parameter Calibration on The Transformation of Rainfall to Runoff Data
}

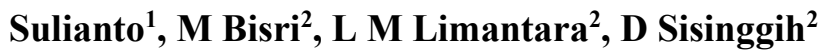 \\ ${ }^{1}$ Civil Engineering Department, University of Muhammadiyah Malang, 65144 \\ Malang, Indonesia \\ ${ }^{2}$ Water Resources Engineering Department, Universitas Brawijaya, 65145 Malang, \\ Indonesia \\ sulianto1967@email.com
}

Received 16-07-2019; revised 31-07-2019; accepted 20-08-2019

\begin{abstract}
This article presents a new model of the DISPRIN Model combination with two different level optimization methods. The new model of DISPRIN Model combination and Differential Evolution (DE) algorithm is called DISPRIN25-DE Models and its incorporation with Monte Carlo Simulation method called DISPRIN25-MC Models. The case study is Lesti Watershed $\left(319.14 \mathrm{Km}^{2}\right)$ in East Java. The model test uses a 10 -year daily data set, from January 1, 2007 to December 31, 2016. Data series Year $2007 \sim 2013$ as a set of training data for calibration and data Year $2014 \sim 2016$ as testing data set for model validation. Running program DISPRIN25-DE Models with input parameter value $C_{-} \min =0, C_{-} \max =1, H_{-} \min =$ $0, H \_$max $=600 \mathrm{~mm}$ obtained best fitness $0.044 \mathrm{~m}^{3} / \mathrm{sec}, \mathrm{NSE}=0.762$ and PME $=-0.059$. The DISPRIN25-MC Models analysis generates a minimum RMSE of $0.056 \mathrm{~m}^{3} / \mathrm{sec}$, NSE $=0.779$, PME $=-0.70$. From the RMSE and NSE indicators it appears that both models can show an equivalent level of performance, but in terms of the PME indicator and iteration time is apparent The DISPRIN25-MC model has worse performance than the two DISPRIN25-DE models.
\end{abstract}

Keywords: automatic, calibration, disprin model, rainfall-runoff

\section{Introduction}

A combination of metaheuristic methods with a conceptual hydrological model can produce a reliable and practical new model applied to divert the rainfall data series into runoff data. In the application the new model can perform automatic calibration by utilizing the rainfall data $[P(t)]$, Evapotranspiration $[E p(t)]$ and runoff $[Q(t)]$ with limited series length [10].

Several new models resulted from a combination of conceptual models of hydrology and metaheuristic methods have been successfully developed by previous researchers, among others; The combination of GA with HBV Modified Model [15], CTSM Algorithm with HBV Model and NAM Model [13], combination of GA with HBV Modelling Model [8], Shuffle Complex Evolution Algorithm (SCE) with AFFDEF Model [4], Combination Dynamically Dimensioned Search (DDS) Algorithm and SCE Algorithm with SWAT 2000 Model [21]. Xin'anjiang Models with SCE Algorithms [1], GA and GA hybrid [20]. 
Metaheuristic methods for the automatic calibration of the Tank Model parameters have been widely proposed by world researchers, including a combination of Particle Swam Optimization (PSO) Algorithms with Tank Models [16], Tank Models combined with Marquard Algorithm [17], GA [13]. The combination of the Tank Models with the PSO Algorithm for flood discharge analysis with the hourly period in urban areas in Taiwan has also performed very well [7]. Multi Tank Model 6 tanks system combined with DDS Algorithm can show better results than the output of the Finite element method (FEM) model [9]. The Tank Model 8 tank system combined with DDS Algorithm and GA can perform well in predicting groundwater fluctuations in Japanese Yamagata. In this case the two developed models can show nearly the same error rate, but the DDS Algorithm based optimization method is more effective in terms of speed reaching convergent conditions $[6,11]$.

This article presents two new models result the combination of the DISPRIN Model (Dee Investigation Simulation Program for Regulating Network) as described by D.G. Jamieson \& J.C. Wilkinson (1972) in Shaw, 1985, page 367 with parameter optimization method based on DE Algorithm and Monte Carlo Simulation Method. The new model of the combination of DISPRIN 25 Model parameters with Algorithm DE called DISPRIN25-DE Model and its merger with Monte Carlo Simulation Method named DISPRIN25-MC Model [18]. The application program system is compiled using M-FILE MATLAB programming language with the reason of practicality in matrix operation and easiness in data management in graphical form. The results of this study are expected to be an alternative solution to solve the problem of limited river flow data which is often a classical constraint in water resource development activities in developing countries.

\section{Material and Methods}

\subsection{Hydrological Model}

The DISPRIN model is included in the lumped model's category which technically can be solved by using the analogy of the Sugawara Tank Model simulation. In "the UK's Water Resources Board's Model DISPRIN", this model was developed at the Dee River research program in the United States [12]. The scheme developed as the basis of simulation is shown Figure 1.

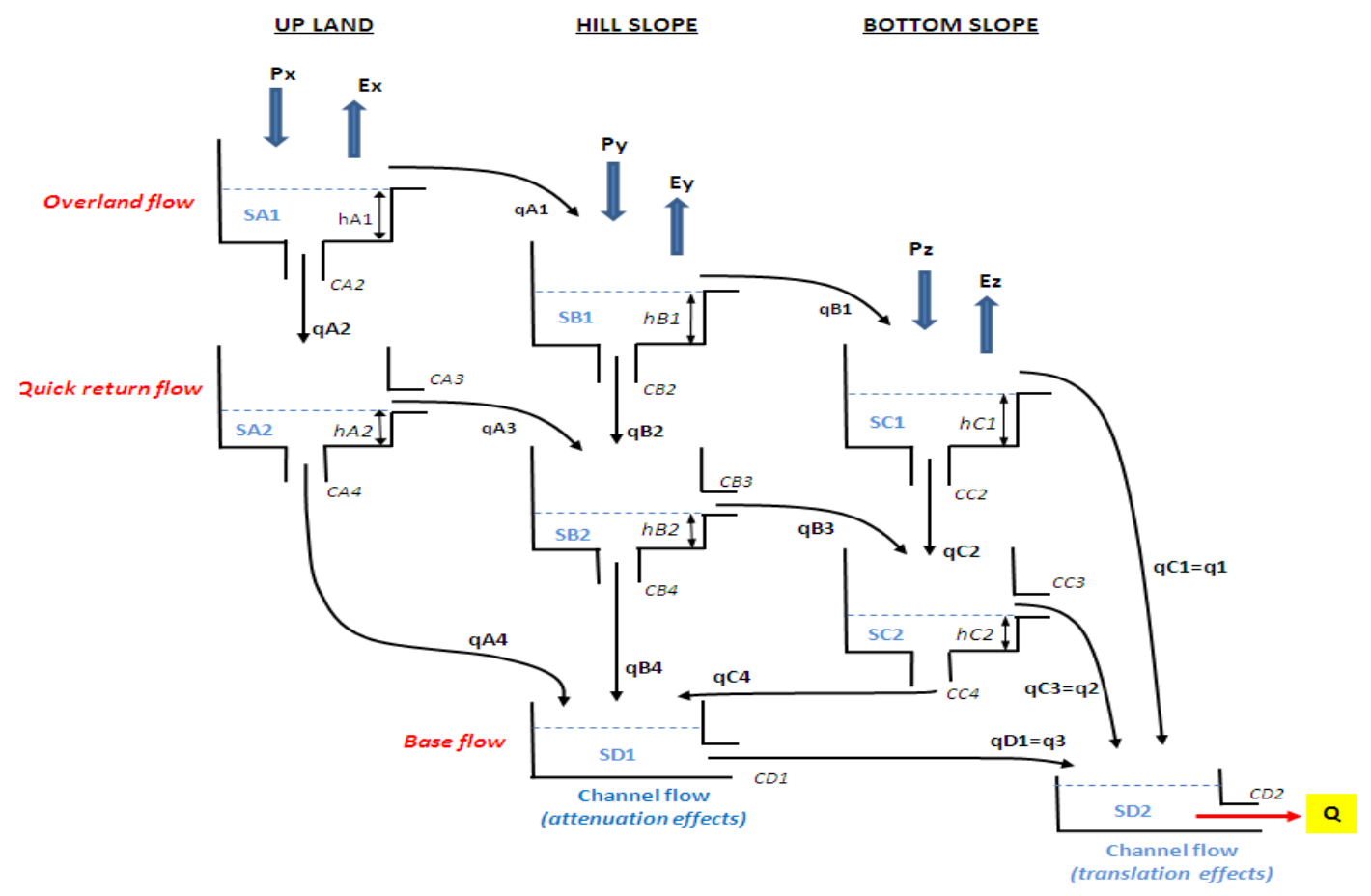

Figure 1. Simulation scheme of DISPRIN Models. 
In the application of the DISPRIN Model a watershed should be divided into 3 zones according to their position and physical characteristics, i.e. up-land zone, hill-slope zone and bottom-slope zone. The up-land zone is located in an upstream basin that is physically sloped by a steep slope, zone hillslope located in a central basin with a relatively moderate surface slope and a bottom-slope zone located downstream of a watershed that tends to have a relatively flat surface slope. Each zone of the watershed is presented by two vertically arrayed tanks. The first tank or upper tank represents the combined surface and intermediate reservoir that contribute to the flow on the surface flow and the intermediate flow. The second tank or bottom tank is the reservoir sub-base that contributes to the flow of the sub-base flow. The tanks in each zone are interconnected with the principle of gravity flow. The horizontal outflow flow from the up-land zone tank group will flow in the hill-slope zone tank group, then the hill-slope zone tank group will drain the water in the bottom slope zone. In the vertical upstream flow, the upper tank will fill the bottom tank when there is sufficient water reservoir in the upper tank. However, if evapotranspiration is so dominant that it cannot be fulfilled by tank water reserves, the water reserves in the lower tanks will be taken at the value of the deficit. This process applies also to two tank groups in the hill-slope basin zone and bottom-slope zone.

The flow through a tank can be solved through the continuity equation. If Tank B1 is reviewed, then the equation applies:

$$
S B 1(t)=S B 1(t-1)+q A 1(t)-q B 1(t)-q B 2(t)+P y(t)-E y(t)
$$

with,

$\operatorname{SBl}(t)=$ Water level Tank B1 period $\mathrm{t}[\mathrm{mm}]$.

$S B 1(t-1)=$ Water level Tank B1 period $\mathrm{t}-1[\mathrm{~mm}]$.

$q A 1(t) \quad=$ Horizontal flow Tank A1 period $\mathrm{t}[\mathrm{mm} /$ day $]$

$P y(t) \quad=$ Precipitation on hill-slope zone period $\mathrm{t}[\mathrm{mm} / \mathrm{day}]$

$E y(t) \quad=$ Evapotranspiration on hill-slope zone period $\mathrm{t}[\mathrm{mm} /$ day $]$

$q B 1(t) \quad=$ Horizontal flow Tank B1period $\mathrm{t}[\mathrm{mm} /$ day $]$

$\begin{aligned} & =c B 1 *[(S B 1(t-1)+S B 1(t)] / 2)-h B 1] \\ q B 2(t) & =\text { Vertical flow Tank B1 period } \mathrm{t}[\mathrm{mm} / \text { day }]\end{aligned}$

$=c B 2 *[S B 1(t-1)+S B 1(t)] / 2]$

$c B 1=$ Horizontal flow coefficient Tank B1

$c B 2=$ Vertical flow coefficient Tank B1

The Tank $D 1$ accommodates the channel flow factor in the attenuation effect component. The water reservoir in this tank is not affected by the evapotranspiration process. The filling of water in the Tank $D 1$ is only influenced by the percolation flow of the three watershed zones. At the beginning of the dry season the base flow in the river is caused by the intermediate flow and sub-base flow components. However, at the end of the dry season when the water reserves in the intermediate zone have been exhausted to meet evapotranspiration needs, the river flow is only supported by the Tank $D 1$. High water catches on Tank Dl stated:

$$
S D 1(t)=S D 1(t-1+q A 4(t)+q B 4(t)+q C 4(t)
$$

In the DISPRIN Model stream flow is the result of translation effect of superposition of surface flow, sub base flow and base flow. The translation effect factor is presented by Tank D2. The water height in Tank D2 is calculated by the equation:

with,

$$
S D 2(t)=S D 2(t-1)+q C 1 t(t)+q C 3 t(t)+q D 1(t)
$$

$S D 2(t)=$ Water lavel Tank D2 period $t$,

$S D 2(t-1)=$ Water level Tank D2 period $(t-1)$,

$q C 1 t(t)=\left(A b / A \_D A S\right) * q C 1(t)$, and

$q C 3 t(t)=\left(A b / A \_D A S\right) * q C 3(t)$. 
$\mathrm{Q}(\mathrm{t})$ is the river runoff period $\mathrm{t}$ at the control point of the watershed in units according to the calculated analysis period. In data analysis with daily period input variables, then river runoff value in $\mathrm{m}^{3} / \mathrm{second}$ unit can be converted by equation:

$$
Q(t)=A \_D A S * q(t) /(86.4)
$$

\subsection{Calibration Model}

\subsubsection{Fitness function}

The parameter calibration model is an analogy of solving the optimization problem to produce the optimal value of DISPRIN Model parameters. The objective function of the optimization process is the minimization of deviation curve of debit training data and the model simulation debit curve. In the metaheuristic method the objective function is expressed as a fitness function. In this article the fitness value is expressed as RMSE which is calculated by the equation [7, 21]:

$$
F=R M S E=\sqrt{\frac{1}{N} \sum_{t=1}^{N}\left[Q_{\text {train }, t}-Q_{\text {sim }, t}\right]^{2}}
$$

with, $F=$ fitness, $Q_{\text {Sim }, t}=$ discharge simulated period $\mathrm{t}, Q_{\text {training }, t}=$ discharge training period $\mathrm{t}, N=$ number of data points.

\subsubsection{Parameter optimization based on Differential Evolution Algorithm (DE)}

DE includes stochastic search methods and population based search. DE has similarities with other evolutionary algorithms (EA), but differs in terms of distance and direction information from the current population used to guide the search process for better solutions. In the field of hydrological modelling the DE algorithm has been successfully applied for parameter optimization of SWAT Model 16 parameters [21]. The DE algorithm contains 4 components, namely; 1) initialization, 2) mutation, 3) recombination or crossover and 4) selection [2]. The process of calibrating the parameters in the DISPRIN25-DE Model systematically can be explained as follows:

1) Input training data set : Evapotranspiration $[E p(t)]$, Rainfall $[P(t)]$, Observation Debit $\left[Q_{\text {training }}(t)\right]$ and area of up-land watershed zone $[A u]$, hill-slope $[A h]$, bottom-slope $[A b]$.

2) Setting parameter $\mathrm{DE}$ : dimension $(D)$, number of individual $(N)$, upper limit $(u b)$ and lower limit (lb) parameter value, and maximum generation number (maximum iteration). The value of $\mathrm{D}$ is corresponding to the number of optimized DISPRIN Model parameters. $D=25$ for DISPRIN25DE Models.

3) Initialization: the generation of the initial value of the $0^{\text {th }}$ generation vector, the variables to $j$ and vector $i$ can be represented by the following notation.

$x_{j, i, 0}=l b_{j}+\operatorname{rand}_{j}(, 1)\left(u b_{j}-l b_{j}\right)$

The random number is generated by the rand function, where the resulting number lies between $(0,1)$. Index $j$ denotes the variable to $j$. In case of minimization of function with 25 variables, then $j$ will be worth $1,2,3, \ldots .25$.

4) Mutation, this process will produce population with size of $N$ vector experiment. Mutation is done by adding two vector differences to the third vector by the following notation :

$$
v_{i, g}=x_{r 0, g}+F\left(x_{r 1, g}-x_{r 2, g}\right)
$$

It appears that two randomly selected vector differences need to be scaled before being added to the third vector, $x_{r 0}, g$. Factor scale $F C(0,1+)$ has real positive value to control population growth rate. The base vector index $r_{0}$ is determined by a random way that different from the index for the target vector, i. Besides being different from each other and different from the index for the vector base and the target vector, the vector index of the increments $r_{1}$ and $r_{2}$ can be chosen once per mutant.

5) Crossover, at this stage DE crosses every vector $\left(x_{i, g}\right)$ with mutant vector $\left(v_{i, g}\right)$, to form the vector of $u_{i, g}$ with the formula. 


$$
u_{i, g}=u_{j, i, g}=\left\{\begin{array}{l}
v_{j, i, g} \rightarrow \text { if }\left(\operatorname{rand}(0,1) \leq \text { Crorj }=j_{\text {rand }}\right. \\
x_{j, i, g} \rightarrow \text { if }\left(\operatorname{rand}(0,1)>\text { Crorj } \neq j_{\text {rand }}\right.
\end{array}\right.
$$

6) Selection, if trial vector $u_{i, g}$ has a goal function value smaller than the target destination function $x_{i, g}$, then $u_{i, g}$ will replace the position $x_{i, g}$ in the population in the next generation. If the opposite happens then the target vector will remain in its position in the population.

The process of analysis of items 4), 5), 6) is done repeatedly from generation 0 to the maximum generation specified (iter_max). Once the maximum generation is reached, then the optimal parameter values and the model simulation debit from the calibration stage are generatedand the model simulation debit from the calibration stage..

\subsubsection{Parameter optimization base on Monte Carlo Simulation Method}

In the field of hydrological modelling Monte Carlo simulations have been successfully used to perform the uncertainty and sensitivity analysis of FORTRAN-HSPF model parameters [14]. The Monte Carlo method can also be used to estimate the value of Tank Model parameters [3] and successfully identify the value and structure of the HBV Model with great satisfaction [19]. The process parameter optimization of DISPRIN25 Model is done through the following stages [14]:

1) Formulate a system of optimization model equations that will be simulated,

2) Input training data sets, namely: $A u, A h, A b, P(i), E p(i)$ and $Q_{o b s}(i)$,

3) Input parameters Monte Carlo Method, ie: number of samples $(N)$, and sample space limit ( $l b$ and $u b$ ) of each variable analyzed, i.e. 25 parameters Model DISPRIN.

4) generates random numbers of uniform distributions or other probabilistic distributions of value $[0,1]$,

5) calculate the appropriate random variable for each model parameter under study based on the number and space of the desired sample,

6) evaluate model performance by using random input parameter value result from step 5) according to the equation developed in step 1 ),

7) steps 4) and 5) repeated as much as the number of samples given, and

8) analyzing and discussing the output of the models presented in graphical form and statistical parameters.

\subsection{Model validation}

Model validation is done by reapplying the DISPRIN25 Model with input set of data testing and the optimal parameter value of the result of the calibration process. The simulated discharge from the model output will be compared with the discharge testing data, and the deviation test uses the RMSE, Nash-Shutclife Efficiency (NSE) and Persistence Model Efficiency (PME) indicators. NSE and PME are calculated by the formula [5].

$$
\begin{aligned}
& N S E=1-\frac{\sum_{t=1}^{N}\left(q_{t}^{s i m}-q_{t}^{o b s}\right)^{2}}{\sum_{t=1}^{N}\left(q_{t}^{o b s}-q_{t}^{\text {mean }}\right)^{2}} \\
& P M E=1-\frac{\sum_{t=1}^{N}\left(q_{t}^{s i m}-q_{t}^{o b s}\right)^{2}}{\sum_{t=1}^{N}\left(q_{t}^{o b s}-q_{t-1}^{o b s}\right)^{2}}
\end{aligned}
$$

\subsection{Case Study}

The position of Lesti Watershed in unity of Brantas watershed is shown in Figure 2. Lesti Watershed has an area of $319.14 \mathrm{~km}^{2}$, divided into Up-land, hill-slope and bottom slope respectively of 67.02 $\mathrm{Km}^{2}, 114.89 \mathrm{Km}^{2}$ and $137.23 \mathrm{Km}^{2}$. The data series of hydroclimatology in this study is data of recording date from January 1, 2011 to December 31, 2013. Evapotranspiration data obtained from the analysis using Penmann Method with data input wind speed, air temperature, air humidity and the duration of solar irradiance monthly. Climatic parameters data obtained from the recording results from Karangkates Station. There are 4 rain gauge stations covered in Lesti Watershed, namely; St. Dampit, St. Turen, St. Wajak and St. Tirtoyudo. Rainfall data recorded in daily period. Average 
regional precipitation is calculated by the Polygon Thiesen Method. Weighting factor of Polygon Thiesen in the four rain stations was $0.380,0.09,0.19$ and 0.34 , respectively. River flow data from the listing of St. AWLR Tawangrejeni is available in the hourly period. The transformation of the discharge data into a daily mean period is calculated by means of an algebraic average. Furthermore, the data series is divided into two groups. The first group as a set of data training for the calibration process and the second group as set of data testing for the model validation process. Set of 7-year training data, the record period of January 1, 2007 until December 31, 2013 and set of data testing from the record results of the period January 1, 2014 to December 31, 2016. Hydroclimological data in daily periods graphically shown Figure 3. Comparison of statistical parameters set of data training and data testing sets are shown in Table 1. Average, minimum, maximum, and varied sets of data testing tend to be larger than the set of data testing.

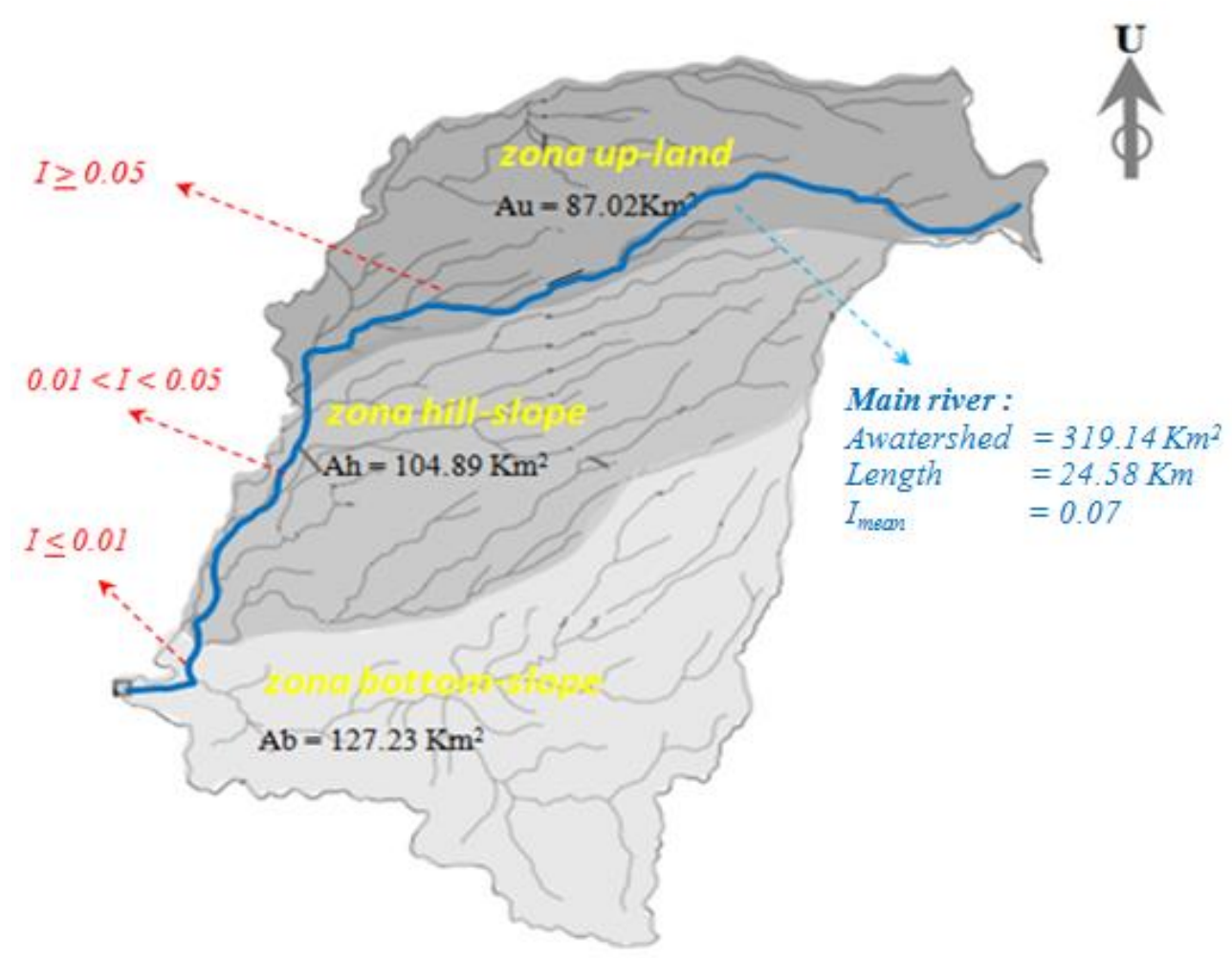

Figure 2. Case studi, Lesti Watershed

Table 1: Comparison of statistical parameters of training and testing data sets

\begin{tabular}{ccccc}
\hline \multirow{2}{*}{ Statistic of parameters } & \multicolumn{2}{c}{ Discharge data $\left(\mathrm{m}^{3} / \mathrm{sec}\right)$} & \multicolumn{2}{c}{ Rainfall data $(\mathrm{mm} /$ day $)$} \\
\cline { 2 - 5 } & Training & Testing & Training & Testing \\
\hline Mean & 17.44 & 18.59 & 6.17 & 6.76 \\
\hline Minimum & 5.91 & 5.99 & 0.00 & 0.00 \\
\hline Maximum & 35.03 & 37.58 & 77.76 & 83.87 \\
\hline Deviation standard & 6.02 & 6.87 & 9.62 & 10.82 \\
\hline
\end{tabular}




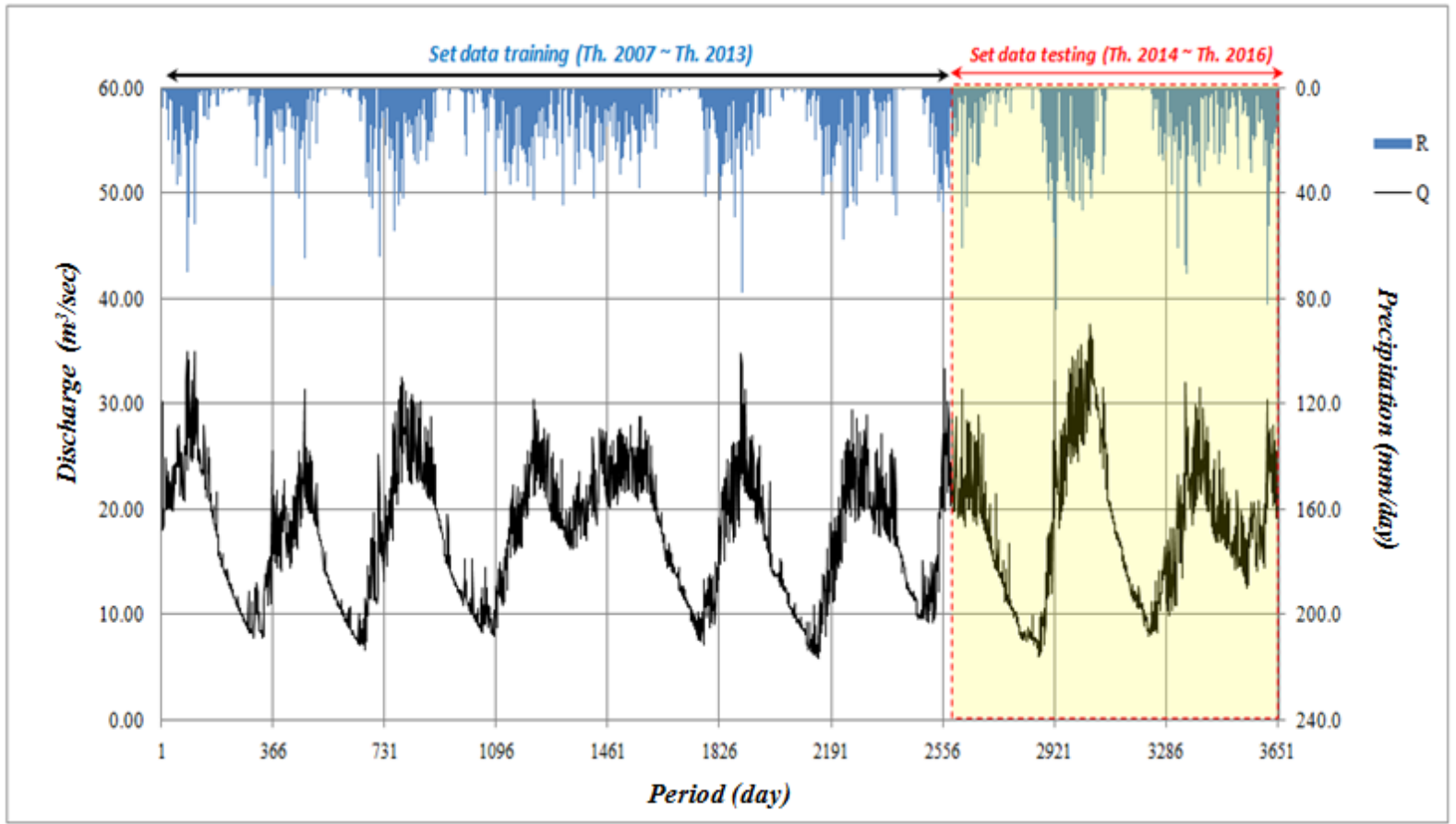

Figure 3: daily training and testing data set

\section{Result and discussion}

The DISPRIN Models implementation reference is still very limited so the feasibility limit of the parameters value becomes difficult to define. Referring to the application of the Sugawara's Tank Model of various references, the minimum (LB_C) and maximum (UB_C) parameters of the tank outlet coefficient are " 0 " and "1" respectively. The initial high water catch and the position of the tank outlet are positive numbers whose value varies depending on the watershed hydrological characteristics being analyzed. In this article the minimum value of the initial parameter of the container and the position of the tank outlet (LB_H) is set to "0", and the maximum value (UB_H) is approached by trial and error. The results of the analysis by utilizing the application DISPRIN25-DE Model generated the relevant UB_H value is $600 \mathrm{~mm}$. Further analysis using input value LB_C $=0$, UB_C $=1, \mathrm{LB} \_\mathrm{H}=0, \mathrm{UB} \_\mathrm{H}=600 \mathrm{~mm}$. The results of the DISPRIN25-DE Models analysis with the parameters inputN $=350$ and Iter_max $=250$ and the results of the DISPRIN25-MCModels analysis with the input sample number of 200,000 are shown in Table 2, Table 3 and Figure 4 to Figure 6.

Table 2: Comparison of model performance indicator values

\begin{tabular}{cccccc}
\hline \multirow{2}{*}{ Performance indicator } & \multirow{2}{*}{ Notation } & \multicolumn{2}{c}{ Calibration stage } & \multicolumn{2}{c}{ Validation stage } \\
\cline { 3 - 6 } & & DE & MC & DE & MC \\
\hline Root Mean Square Error & RMSE & 0.044 & 0.056 & 0.086 & 0.100 \\
\hline Nash-Sutcliffe Efficiency & NSE & 0.762 & 0.779 & 0.727 & 0.769 \\
\hline Persistence Model Efficiency & PME & -0.059 & -0.700 & -0.128 & -0.505 \\
\hline Time of iteration & t_iteration & 126.67 & 172.59 & - & - \\
\hline
\end{tabular}

The best fitness value or minimum RMSE at the calibration stage of the DISPRIN25-DE Models is obtained $0.044 \mathrm{~m}^{3} / \mathrm{sec}$ and the analysis of the DISPRIN25-MC Models with the sample input quantity of 200,000 is obtained $0.056 \mathrm{~m}^{3} / \mathrm{sec}$. The progress of achieving the minimum RMSE values of the two models is shown in Figures 4 and 5. Based on the RMSE and NSE indicators both models can perform as well, but on the PME indicator the both model gives a negative value which means it does not 
perform well, The DISPRIN25-DE model has much better performance than the DISPRIN25-MC Model. Model performance in the validation stage is generally decreased although not significant. This is understandable because the data training sets and data testing sets have different statistical parameters. In terms of the iteration the DISPRIN25-MC Model shows 30\% longer than the DISPRIN25-DE model. From the various considerations, it can be concluded that the process optimization parameter DISPRIN25 Model based DE Algorithm is more effective than the analysis by applying Monte Carlo Simulation Method.

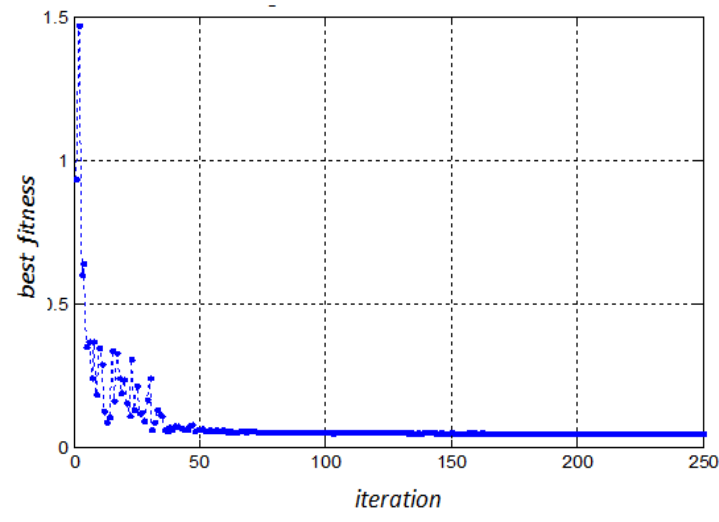

Figure 4: Progress the best fitness value of DE Algorithm

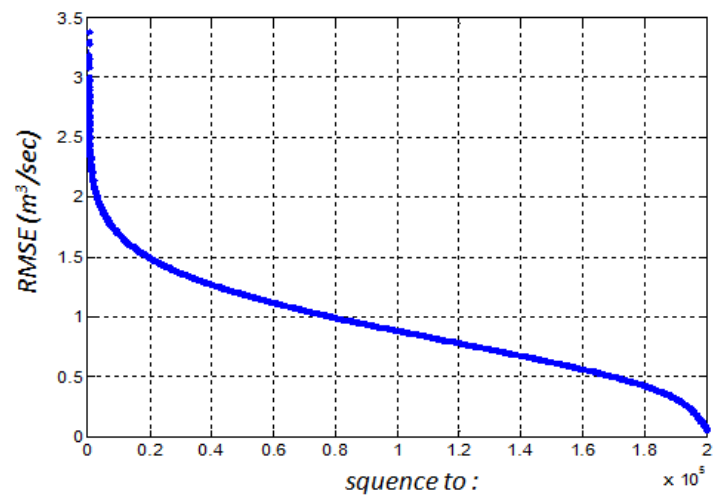

Figure 5: RMSE value of Monte Carlo Simulation results Sorted from large to small

Table 3: DISPRIN25 Models optimum parameters

\begin{tabular}{|c|c|c|c|c|c|}
\hline \multirow{2}{*}{ Parameter } & \multirow{2}{*}{ Description } & \multicolumn{2}{|c|}{ Constraint } & \multicolumn{2}{|c|}{ Optimum parameters } \\
\hline & & LBj & UBj & $\mathrm{DE}$ & $\mathrm{MC}$ \\
\hline$h A 1$ & height of surface outlet up-land zone & 0.00 & 600.00 & 0.07 & 69.95 \\
\hline$h A 2$ & height of sub surface outlet up-land zone & 0.00 & 600.00 & 600 & 433.8 \\
\hline$C A 2$ & infiltration coefficient up-land zone & 0.00 & 1.00 & 0.348 & 0.502 \\
\hline$C A 3$ & sub surface coefficient up-land zone & 0.00 & 1.00 & 0.499 & 0.0075 \\
\hline CA4 & percolation coefficient up-land zone & 0.00 & 1.00 & 0.18 & 0.926 \\
\hline$S A 10$ & initial storage of tank SA1 & 0.00 & 600.00 & 155.15 & 599.79 \\
\hline$S A 20$ & initial storage of tank $S A 2$ & 0.00 & 600.00 & 0 & 434.53 \\
\hline$h B 1$ & height of surface outlet hill-slope zone & 0.00 & 600.00 & 0 & 592.27 \\
\hline$h B 2$ & height of sub surface outlet hill-slope zone & 0.00 & 600.00 & 500.31 & 281.28 \\
\hline$C B 2$ & infiltration coefficient hill-slope zone & 0.00 & 1.00 & 0.672 & 0.954 \\
\hline$C B 3$ & sub surface coefficient hill-slope zone & 0.00 & 1.00 & 0.906 & 0.898 \\
\hline$C B 4$ & percolation coefficient hill-slope zone & 0.00 & 1.00 & 0.293 & 0.768 \\
\hline SB1_0 & initial storage of tank $S B 1$ & 0.00 & 600.00 & 67.72 & 213.99 \\
\hline$S B 20$ & initial storage of tank SB2 & 0.00 & 600.00 & 600 & 160.06 \\
\hline$h C 1$ & height of surface outlet bottom-slope zone & 0.00 & 600.00 & 0 & 434.89 \\
\hline$h C 2$ & height of sub surface outlet bottom-slope zone & 0.00 & 600.00 & 596.49 & 269.24 \\
\hline$C C 2$ & infiltration coefficient bottom-slope zone & 0.00 & 1.00 & 0.846 & 0.684 \\
\hline$C C 3$ & sub surface coefficient bottom-slope zone & 0.00 & 1.00 & 0.26 & 0.547 \\
\hline$C C 4$ & percolation coefficient bottom-slope zone & 0.00 & 1.00 & 0.506 & 0.829 \\
\hline SC1 0 & initial storage of tank SC1 & 0.00 & 600.00 & 164.48 & 221.5 \\
\hline$S C 20$ & initial storage of tank SC2 & 0.00 & 600.00 & 600 & 79.31 \\
\hline$C D 1$ & runoff coefficient & 0.00 & 1.00 & 0 & 0.007 \\
\hline$C D 2$ & runoff coefficient & 0.00 & 1.00 & 0.007 & 0.386 \\
\hline SC1 0 & initial storage of tank (attenuation effect) & 0.00 & 600.00 & 282.57 & 369.87 \\
\hline SC2 0 & initial storage of tank (translation effect) & 0.00 & 600.00 & 591.1 & 2.97 \\
\hline
\end{tabular}



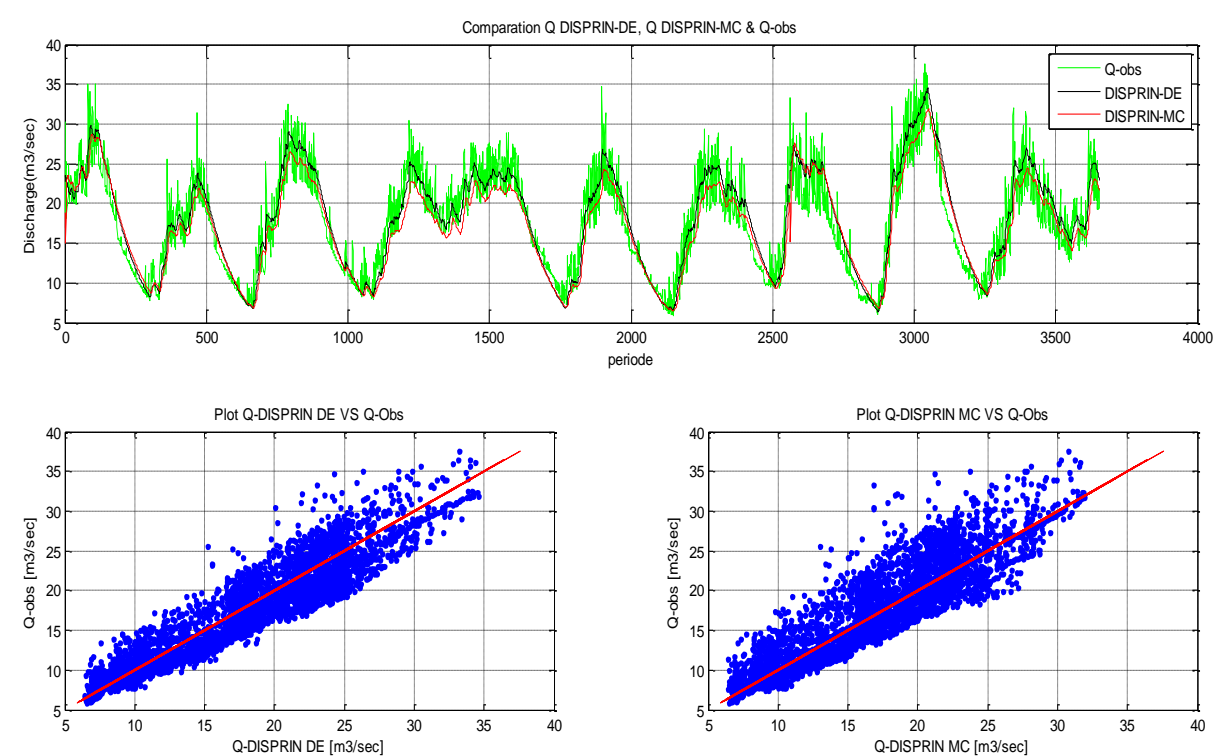

Figure 6: Comparison of the discharge observed data series and the model output

The comparison of the flow curve data and the curve from the model outcomes at the calibration stage and validation stage is shown Figure 6. Results from the DISPRIN25-MC model outcomes appear to be different at high flow conditions, where the results obtained tend to be under estimated. The resulting flow curves of the both models at the calibration stage can generally follow the seasonal trend of the training data flow curve. In low flow, normal flow and high flow conditions tend to place themselves in a moderate position. Fluctuations in the sharp flows that occur due to the high rainfall intensity in the daily period cannot be responded well. This condition is the cause of the low value of the resulting PME indicator. Taking to the simulation scheme and the total equation of the Model DISPRIN25 flow as shown in Figure 1, the existence of the translation effect factor (channel flow) is likely to be the factor causing this condition. The existence of the translation effect factor presented by a tank with a bottom outlet actually becomes an obstacle to model efforts in anticipating the fluctuation of sharp flows. Rapid flow changes due to the high rainfall intensity occurring in the accumulation of up-land zone tanks, hill-slope and bottom-slope are muted in translation effect tanks and are delivered slowly. In the minimum RMSE condition the optimal value of the DISPRIN25 Model parameter is shown in Table 3 in column [5,6]. The optimal value of DISPRIN25 Model parameters from the output of the two models gives different results because the resulting performance level is also significantly different.

\section{Conclusions}

Based on the RMSE, NSE, PME and iteration indicators the DE Algorithm is proven to work more effectively than Monte Carlo Simulation Methods in solving the parameterization problem of the DISPRIN25 Model. Testing Model DISPRIN25-DE on Lesti Watershed $\left(319.14 \mathrm{Km}^{2}\right)$ with daily data set can show good performance both calibration stage and validation stage. Generally generated flow curves can follow the seasonal trend of the observation flow curve. In low flow conditions, the normal flow as well as the high flow curve from the outline of the model tend to place themselves in a moderate position. Fluctuations in the sharp flows that occur due to the high rainfall intensity of the daily period cannot be responded well. This condition is the cause of the low value of the resulting PME indicator. The translation effect factor presented by a tank with a basic outlet actually hampers the efforts of the DISPRIN25 Model in anticipating the occurrence of sharp fluctuations. Rapid flow changes due to the high rainfall intensity occurring in the accumulation of up-land zone tanks, hillslope and bottom-slope are muted in translation effect tanks and are delivered slowly. The optimal 
value of DISPRIN25 Model parameters from the output of the two models gives different results because the resulting performance level is also different.

\section{References}

[1] Bao H. J, Wang L, Li Z. J, Zao L. N, Guo-ping ZHANG, 2008, Hydrological daily rainfallrunoff simulation with BTOPMC model and comparison with Xin'anjiang model, Water Science and Engineering, 2010, 3(2): 121-131, doi: 10.3882/j.issn.1674-2370.2010.02.001, http://www.waterjournal.cn, e-mail: wse2008@vip.163.com

[2] Budi Santosa \& Paul Willy, 2011, Metoda Metaheuristik Konsep dan implementasi, Cetakan pertama, Guna Widya, Surabaya, Indonesia.

[3] Chen C, Shrestha D.L., Perez G.C., Solomatine D., 2006, Comparison of methods for uncertainty analysis of hydrologic models, 7th International Conference on Hydroinformatics HIC 2006, Nice, FRANCE.

[4] Darikandeh Dorsa, Akbarpour Abolfazl, Bilondi Mohsen Pourreza \& Hashemi Seyyed Reza, 2014, Automatic calibration for Estimation of The Parameters of Rainfall - Runoff Model, SCIJOUR, Journal of River Engineering, Volume 2, Issue 8 2014, http://www.scijour.com/jre.

[5] Gupta, Sorooshian \& Yapo, 1999, "Status of automatic calibration for hydrologic Models: Comparation With Multi Level Expert Calibration", Journal of Hydrologic Engineering, Vol. 4, No. 2, April, 1999. ASCE, ISSN:1084-0699/99/0002-0135-0143, http://www.ascelibrary.org.

[6] Huang X. L. \& Xiong J., 2010, Parameter Optimization of Multi-Tank Model with Modified Dynamically Dimensioned Search Algorithm, Proceedings of the Third International Symposium on Computer Science and Computational Technology (ISCSCT '10), Jiaozuo, P. R. China, 14-15, August 2010, pp. 283-288, ISBN 978-952-5726-10-7, (C) 2010 ACADEMY PUBLISHER, AP-PROC-CS-10CN007.

[7] Hsu \& Yeh, 2015, Study on Flood Para-Tank Model Parameters with Particle Swarm Optimization, Journal of Information Hiding and Multimedia Signal Processing, Ubiquitous International Volume 6, Number 5, September 2015, @ 2015 ISSN 2073-4212

[8] Jonsdottir Harpa, Madsen Henrik \& Palsson Olafur Petur, 2005, Parameter estimation in stochastic rainfall-runoff models, ELSEVIER, Journal of Hydrology 326 (2006) 379-393.

[9] Kenji T., Yuzo O., Xiong J. \& Koyama T, 2008, Tank Model and its Application to Predicting Groundwater Table in Slope, Chinese Journal of Rock Mechanics and Engineering, Vol.27 No.12 Dec, 2008, CLC number : P 642.22 Document code : A Article ID : 1000-6915(2008)12-2501-08.

[10] Kim Oong H., Paik Kyung R., Kim Hung S. \& Lee, 2005 Dong R., A Conceptual Rainfall runoff Model Considering Seasonal Variation, ARTICLE in HYDROLOGICAL PROCESSES · DECEMBER 2005Impact Factor: 2.68 · DOI: 10.1002/hyp.5984ADVANCES IN HYDRO-SCIENCE AND -ENGINEERING, VOLUME VI, http://www.researchgate.net/publication/ 227599393

[11] Kuok King Kuok, Sobri Harun and Po-Chan Chiu, 2011, Comparison of Particle Swarm Optimization and Shuffle Complex Evolution for Auto-Calibration of Hourly Tank Model's Parameters, Int. J. Advance. Soft Comput. Appl., Vol. 3, No. 3, November 2011, ISSN $2074-$ 8523; Copyright (C) ICSRS Publication, 2011, www.i-csrs.org

[12] M. Shaw, Elizabeth, 1985, Hydrology in Practice, Van Nostrand Reinhold (UK) Co. Ltd.

[13] Ngoc T. A., Hiramatsu K. \& Haramada M., 2012, Optimizing Parameters for Two Conceptual Hydrological Models Using a Genetic Algorithm: A Case Study in the Dau Tieng River Watershed, Vietnam, JARQ 47 (1), 85 - 96 (2013) http://www.jircas.affrc.go.jp.

[14] Ramires J.D, Camacho R, McAnally W, Martin J, 2012, Parameter uncertainty methods in evaluating a lumped hydrological model, Obrasy Proyectos 12, 42-56. 
[15] Saibert Jan, 2000, Multi-criteria Calibration of Conceptual Runoff Model Using a Genetic Algorithm, Hydrology and Earth System Sciences, 4(2), 215-224 (2000) EGS.

[16] Santos, 2011, Application of a particle swarm optimization to the Tank Model, Risk in Water Resources Management (Proceedings of Symposium H03 held during IUGG2011 in Melbourne, Australia, July 2011) (IAHS Publ. 347, 2011).

[17] Setiawan B., Fukuda T. \& Nakano Y., 2003, Developing Procedures for Optimization of Tank Model's Parameters, Agricultural Engineering International: the CIGR Journal of Scientific Research and Development.

[18] Tolson B. A. \& Shoemaker C. A., 2007, Dynamically dimensioned search (DDS) algorithm for computationally efficient watershed model calibration, ATER RESOURCES RESEARCH, VOL. 43, W01413, doi:10.1029/2005WR004723, 2007, Copyright 2007 by the American Geophysical Union. 0043-1397/07/2005WR004723\$09.00

[19] Uhlenbrook S, Seibert J, Leibundgut C, Rodhe A, 1999, Prediction uncertainty of conceptual rainfallrunoff models caused by problems in identifying model parameters and structure, Hydrological Sciences-Joumal-des Sciences Hydrologiques, 44(5) October.

[20] Wang W. C., Cheng C. T., Chau K. W \& Xu D. M., 2012, Calibration of Xinanjiang model parameters using hybrid genetic algorithm based fuzzy optimal model, (C) IWA Publishing 2012, Journal of Hydroinformatic, 14.3 - 2012, 785 W.-C. Wang et al. | Calibration of Xinanjiang model parameters using HGA based FOM.

[21] Zhang, Srinivasan, Zhao \& Liew (2008), Evaluation of global optimization algorithms for parameter calibration of a computationally intensive hydrologic model, HYDROLOGICAL PROCESSES, Published online in Wiley InterScience, www.interscience.wiley.com. 